\title{
Élites y elecciones en México: estrategias discursivas y elementos legitimadores en el proceso de selección de los consejeros de los OPLES (2015) Elites and elections in Mexico: discursive strategies and legitimating elements in the selection process of the OPLES councilors (2015)
}

Ignacio Camargo-González * y María Esther Neri-Olmos**

Recibido: Febrero 2019

Aceptado: Marzo 2019
Palabras Clave

Elitismo en México, procesos electorales, estrategias discursivas, elementos legitimadores, reclutamiento de funcionarios públicos.

\section{Keywords}

Elitism in Mexico, electoral processes, discursive strategies, legitimizing elements, recruitment of public officials.
En este artículo se presenta un análisis de las estrategias discursivas utilizadas por los consejeros electorales, del Consejo General (CG) del Instituto Nacional Electoral (INE), durante el proceso de selección de los consejeros que se integraron en los Organismos Públicos Locales Electorales [OPLES] en la elección local del 2015. El enfoque, el procedimiento y el análisis de los datos se llevaron a cabo desde la perspectiva de la Teoría Fundamentada (Grounded Theory). El argumento que se esgrime es que el reclutamiento de los consejeros de los OPLES se realiza de entre la propia élite política especializada para esta función, por ello es que los funcionarios responsables deben recurrir a diversas estrategias discursivas legitimadores de una selección dirigida.

Abstract
This article presents an analysis of the discursive strategies used by the electoral councilors, of the
General Council (CG) of the National Electoral Institute (INE), during the selection process of the
councilors that were integrated in the Local Public Electoral Organizations [OPLES] in the local
election of 2015. The approach, procedure and data analysis were carried out from the perspective
of the Grounded Theory. The argument that is made is that the recruitment of the OPLES councilors
is done from within the specialized political elite for this function that is why the responsible
officials must resort to different discursive strategies that legitimize a directed selection.

Introducción

'La historia es un cementerio de aristocracias' 1

Vilfredo Pareto

En este artículo se presenta un análisis de las estrategias discursivas y de los elementos legitimadores utilizadas por los consejeros

\footnotetext{
* Es profesor e investigador de la Facultad de Ciencias Políticas y Sociales, de la Universidad Autónoma de Chihuahua, es doctor en Ciencias Sociales, miembros del Sistema Nacional de Investigadores del Consejo Nacional de Ciencia y Tecnología (Nivel I) y recibe correspondencia en Avenida Henry Dunant No. 4612, Zona PRONAF, en Ciudad Juárez, Chihuahua, México. También se le puede localizar en el número teléfono (656) 6168888 y en el email: icamargo0202@yahoo.com.mx.

** Es licenciada en derecho, egresada de la maestría en Administración Pública de la Facultad de Ciencias Políticas y Sociales, de la Universidad Autónoma de Chihuahua. Recibe correspondencia en Avenida Henry Dunant No. 4612, Zona PRONAF, en Ciudad Juárez, Chihuahua, México. Contacto en número teléfono (656) 61688 88. También se le puede localizar en el número teléfono (656) 61688 88 y en el email: nerijuarez21@hotmail.com
}

1 La idea completa de Pareto cuando se refiere al hecho de que 'la historia es un cementerio de aristocracias', nos remite a que la historia de la humanidad (o cuando menos de la sociedad occidental) es una repetición permanente del mismo fenómeno: unos cuantos mantienen el poder y dominan a la mayoría. Además, este modelo de distribución del poder ha sido omnipresente y sistemático. Cfr. Pareto, Vilfredo, Tratado de 
electorales, del Consejo General (CG) del Instituto Nacional Electoral (INE), durante el proceso de reclutamiento de los consejeros que se integraron en los Organismos Públicos Locales Electorales [OPLES] en la elección local del 2015. Aquí se describe, en un primer momento, el procedimiento que se inicia el 6 de junio de 2014, con la aprobación del Consejo General del Instituto Nacional Electoral [INE] del Acuerdo INE/CG44/2014 mediante el cual se aprobaron los "Lineamientos para la designación de consejeros presidentes y consejeros electorales de los organismos públicos locales" y que concluye con la designación de los consejeros presidentes y consejeros electorales para las 18 entidades que tendrían elecciones en ese año: 1. Baja California Sur, 2. Campeche, 3. Colima, 4. Chiapas, 5. Distrito Federal, 6. Guanajuato, 7. Guerrero, 8. Jalisco, 9. México, 10. Michoacán, 11. Morelos, 12. Oaxaca, 13. Nuevo León, 14. Querétaro, 15. San Luis Potosí, 16. Sonora, 17. Tabasco y 18. Yucatán.

El argumento que se esgrime en este documento es que al reclutamiento de los consejeros electorales de los OPLES se realiza de entre la propia élite política ${ }^{2}$; de aquí el patrón de la 'pérdida de legitimidad de las instituciones' responsables de la organización de los procesos electorales se mantenga en el tiempo y en cualesquiera de las versiones institucionales que ha marcado la legislación desde su concepción originaria en 1990. Resulta por demás evidente que los grupos dominantes, al interior de los propios partidos políticos, sean quienes mantengan el control de tales designaciones. No obstante algunos cambios de forma, en el fondo el locus del poder y su ejercicio en las designaciones se mantiene inalterado cuando menos desde 1997.

Tal y como iremos demostrando a lo largo de este análisis, la clase política se encargará de colonizar [ocupar], por cualquier medio posible, todo rendija en la esfera de la política para mantener su preponderancia [o hegemonía]. En el caso que nos ocupa, será el partido Revolucionario Institucional (PRI) quien, para lograr este cometido, propone en la ley reglamentaria ingeniosos mecanismos con procedimentales legitimadores que le permitan mantener esa colonización y el control de los órganos electorales, aquellos que alguna vez se definieron como eminentemente 'ciudadanos'.

El modelo electoral mexicano, cuyo diseño procede de los lineamientos del Código Federal de Instituciones y Procedimientos Electorales [COFIPE] de 1990, experimentó un enorme desgaste que llevó a modificaciones significativas a partir de la reforma política del 31 de enero del 2014. Hasta antes de esa fecha, como se ha señalado, las elecciones en México eran administradas por un modelo binario integrado por un sistema federal y 32 versiones similares que tenían aplicación en cada una de las entidades federativas. No obstante la soberanía que cada estado posee respecto de su régimen interno, según se propone en la Constitución Política de los Estados Unidos Mexicanos [CPEUM], las reglamentaciones electorales locales fueron diseñadas para que no contravinieran a la CPEUM ni al propio COFIPE.

Por ello fue que una de las estrategias a seguir por el poder legislativo federal, para tratar de recuperar esta credibilidad que habían perdido las autoridades electorales locales, fue la de la centralización del proceso de selección; se quitó a los gobernadores de los estados el poder de decidir sobre la integración de los consejos de lo que hoy se conoce como OPLES. La sociedad civil y sobre todo los partidos de oposición, que fueron siempre excluidos en la distribución de algún puesto en esos consejos, eran quienes reclamaban la parcialidad del árbitro electoral local; el gobernador en turno (que casi siempre obtiene la mayoría calificada en el congreso local) era quien decidía sobre la integración del consejo general de la entidad que gobernaba.

De aquí que la reforma política del 2014, en un intento por recuperar los elementos que minaban el prestigio de las instituciones electorales (sobre todo las locales) reasignó esta tarea al consejo general del INE. Previo a esta modificación constitucional, lo que se observaba en las reglamentaciones electorales, es que formalmente las diversas competencias electorales en las entidades, no mostraban diferencias de criterio o procedimiento con respecto de la legislación electoral federal.

Esta reforma político-electoral, del 31 de enero de 2014, era impostergable debido al desgaste que habían experimentado las instituciones electorales [federal y locales] luego de 24 años de funcionamiento pero, sobre todo, de las dudas que suscitó la administración electoral [IFE-TRIFE-FEPADE] en sus dos vertientes. El procedimiento de esta reforma siguió el curso previsto por la CPEUM; una serie de cambios a las reglas formales en las que se asienta 'el deber ser' de los procedimientos electorales que, una vez discutida y aprobada por el Congreso de la Unión y la mayoría de las legislaturas estatales, fue promulgada 31 de enero de 2014 por el Presidente de la República. Más tarde, el 10 de febrero de 2014, fue publicado en el mismo Diario Oficial de la Federación [DOF] el "Decreto por el que se reforman, adicionan y derogan diversas disposiciones de la Constitución Política de los Estados Unidos Mexicanos, en materia política-electoral"3.

Será en este decreto de reforma, que toma como base la reglamentación anterior [del COFIPE de 1990], en la que se especifican las disposiciones que modifican la denominación,

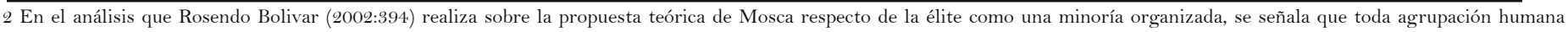

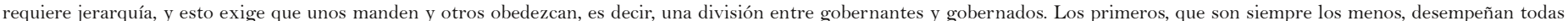

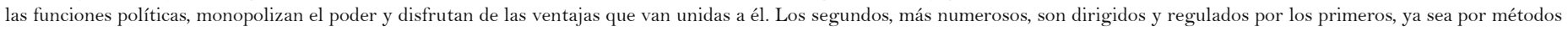
legales o por mecanismos arbitrarios y violentos.

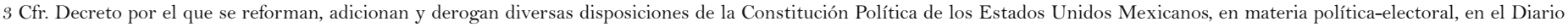
Oficial de la Federación, del 10 de febrero del 2014.

14 Vol. 9 Núm. 16 Enero-junio 2019 
estructura, funciones y objetivos del Instituto Federal Electoral [IFE] para transformarse en Instituto Nacional Electoral [INE]. Aquí se destacan, entre otras, la modificación de la integración de su Consejo General y la inclusión de nuevas atribuciones. Fue así que el 3 de abril de 2014, el pleno de la Cámara de Diputados designó al Consejero Presidente y a los diez Consejeros Electorales del Consejo General del INE4. Al día siguiente, el 4 de abril de 2014, los Consejeros electos rindieron protesta en sesión convocada para tal efecto conforme se disponía en el artículo 110.7 del cuasi derogado COFIPE.

Este fue el primer paso de la transición; la integración del Consejo General del $\mathrm{INE}^{4}$, en términos de lo establecido en el artículo 41, Base V, Apartado A, párrafo segundo de la CPEUM. Y, no sería sino hasta el 23 de mayo de 2014, que se publicó la Ley General de Instituciones y Procedimientos Electorales [LEGIPE] en el DOF, iniciando su vigencia el día 24 de mayo de 2014. Posteriormente, el 6 de junio de ese año, se aprobó el Acuerdo INE/CG46/2014, mediante el que se determinaba la integración de las comisiones permanentes y temporales que contemplaba para su operación el Consejo General, entre ellas la de la Comisión de Vinculación con los OPLES, quedando integrada por: Marco Antonio Baños Martínez [presidente], Adriana Margarita Favela Herrera [integrante], Ciro Murayama Rendón [integrante] y Arturo Sánchez Gutiérrez [integrante] ${ }^{5}$.

Posteriormente, el 6 de junio de 2014, el propio Consejo General aprobó el Acuerdo INE/CG44/2014 mediante el cual fueron aprobados los "Lineamientos para la designación de consejeros presidentes y consejeros electorales de los organismos públicos locales". De igual forma, sería el día 20 de ese mismo mes que el Consejo General, en sesión extraordinaria, emitiría el acuerdo INE/CG/69/2014 mediante el cual aprobó el modelo de convocatoria para la designación de consejeros presidentes y consejeros electorales de los OPLES.

Más adelante, el 13 de agosto de 2014, el mismo consejo aprobó, también en sesión extraordinaria el Acuerdo INE/CG113/2014, mediante el cual emitió los Lineamientos para la aplicación y dictamen del ensayo presencial que presentaron las 25 aspirantes mujeres y los 25 aspirantes hombres de cada entidad federativa que obtuvieron la mejor puntuación en el examen de conocimientos en el proceso de selección y designación a los cargos de consejero presidente y consejeros electorales de los organismos públicos locales, esto en acato de lo que dispuso la Sala Superior del Tribunal Electoral del Poder Judicial de la Federación, en las sentencias SUP-JDC-498/2014, SUP-JDC-499/2014 y SUP-JDC-

\section{$500 / 2014$.}

El nuevo entramado jurídico, con en que se procedía a la centralización de los anteriormente denominados Consejos Generales de las 32 entidades federativas, se ubicó en el Transitorio Noveno del Decreto con el que se reformaban, adicionaban y derogaban diversas disposiciones de la CPEUM, en materia política electoral, en el que se señalaba que sería el propio Consejo General del INE el órgano colegiado que designaría a los nuevos consejeros de los OPLES, en términos de lo dispuesto por el inciso c) de la fracción IV del artículo 116 constitucional. Asimismo, se señalaba que los mismos consejeros continuarían en su encargo hasta que se realizaran las nuevas designaciones y que el Consejo General llevaría a cabo los procedimientos para que el nombramiento de los consejeros electorales se realizara con antelación al siguiente proceso electoral posterior a la entrada en vigor de este decreto.

De igual forma, se disponía en los artículos 2, 31, 42, 44, 100, y 101 de la propia Ley General de Instituciones y Procedimientos Electorales [LEGIPE], que reglamenta las normas constitucionales relativas a la integración de los organismos electorales, que: sería el Consejo General quien integraría la Comisión de Vinculación con los Organismos Públicos Locales, que funcionaría permanentemente y estaría conformada por cuatro consejeros; que es una atribución del Consejo General designar y remover, en su caso, a los Presidentes y Consejeros Electorales de los Organismos Públicos Locales, conforme a los procedimientos establecidos en la propia Ley, así como dictar los Acuerdos necesarios para hacer efectivas sus atribuciones; que se establecen los requisitos para ser consejero electoral local; que, para la elección del Consejero Presidente y los Consejeros Electorales de los Organismos Públicos Locales, la Comisión de Vinculación con los Organismos Públicos Locales tendría a su cargo el desarrollo, vigilancia y la conducción del proceso de designación.

También se dispuso en la legislación, mediante el artículo Transitorio Décimo, que para los Procesos Electorales Locales, cuya Jornada Electoral se realice en 2015, el Consejo General debería desarrollar el proceso de designación de los integrantes de los consejos generales de los OPLES, en los términos de los párrafos 1, 2 y 3 del inciso c) de la fracción IV del artículo 116 de la Constitución Política de los Estados Unidos Mexicanos, a más tardar el 30 de septiembre de 2014. Respecto a las demás entidades federativas, la elección se habrá de realizar con antelación al inicio de su siguiente Proceso Electoral. Un detalle interesante que se debe mencionar en este momento, es que los nombramientos de los consejeros deberían realizarse de forma escalonada. Este proceso de relevo previsto se

4. Cfr. Decreto publicado en el Diario Oficial de la Federación, del 4 de abril del 2014.

5 Cfr. Acuerdo del Consejo General del Instituto Nacional Electoral INE/CG46/2014. 
realizó a semejanza del Consejo General del INE y buscaba, se menciona, aprovechar la experiencia de los consejeros y garantizar un relevo terso de los consejeros. Por ellos fue que se propusieron distintos periodos para el encargo de consejeros en los siguientes términos: a) Tres consejeros que durarán en su encargo tres años; b) Tres consejeros que durarán en su encargo seis años, y c) Un consejero que durará en su encargo siete años.

Fue así que, mediante el Acuerdo INE/CG/69/2014 del Consejo General, emitido en la sesión extraordinaria del 20 de junio de 2014, se aprobó el modelo de convocatoria para la designación de Consejeros Presidentes y Consejeros Electorales de los OPLES. En este documento, emitido mediante el Acuerdo INE/CG/69/2014, se dispuso que el plazo de recepción de las solicitudes de registro de aspirantes a ocupar un cargo para el órgano superior de Dirección de los OPLES, sería entre el 7 y el 11 de julio de 2014, así como los días 14 y 15 del mismo mes y año. Y, sería en el Apartado Octavo, del capítulo II, párrafo 2, inciso b), de los Lineamientos en los que se establecería que corresponde a esta Comisión de consejeros del Consejo General de INE el instrumentar, conforme a la Ley General y a los propios Lineamientos, el proceso para la selección y designación de las y los integrantes del órgano superior de dirección de los OPLES

En este documento, en el que se proponía una especie de transparencia, equidad de género, inclusión y democratización de la distribución de los cargos de consejeros, se disponía en el capítulo V, Apartado Vigésimo del mismo documento de los Lineamientos, que en cada una de las etapas: i. Se procurará atender la equidad de género y una composición multidisciplinaria; ii. En los casos específicos que se requiera, también se procurará atender a una integración multicultural; iii. Que las y los aspirantes serán evaluados en atención a los principios de objetividad e imparcialidad y sin discriminación motivada por origen étnico, género, condición social, orientación religiosa, preferencias sexuales, estado civil o cualesquier otra que atente contra la dignidad humana y tenga por objeto anular o menoscabar los derechos y libertades de las personas; y, iv. En la integración del órgano superior de dirección de los OPLES se procuraría una conformación de por lo menos tres consejeros electorales del mismo género.

De aquí que la comisión responsable del consejo general del INEE se propuso la implementación de un procedimiento se selección que observara tales principios. Primero lanzó una convocatoria; en segundo lugar, realizó una revisión de los documentos que presentaron los precandidatos; $y$, en tercero, dispuso que los aspirantes que hubiesen cumplido con los requisitos legales presentarán un examen de conocimientos y, en su caso, un ensayo cuya evaluación sería tomada en cuenta al momento de valorar su idoneidad y capacidad para el cargo ${ }^{6}$. De igual forma, se consideró pertinente que, a petición de la propia Comisión, se podría pedir a una institución de educación superior, de investigación o evaluación, la elaboración de los reactivos y/o la aplicación y evaluación de los exámenes y podría convenir con universidades, instituciones de educación superior o de investigación, la aplicación y el dictamen de los ensayos presentados por los candidatos.

Las entidades federativas en las que se realizó este primer ejercicio, de selección de consejeros, fueron las que tendrían elecciones locales intermedias o finales y en las que funcionarían por primera vez los OPLES centralizados [con designación de consejeros por parte de esta comisión de consejeros del Consejo General]. Así, los consejeros presidentes y consejeros electorales designados de tales OPLES fueron para las entidades siguientes: 1. Baja California Sur, 2. Campeche, 3. Colima, 4. Chiapas, 5. Distrito Federal, 6. Guanajuato, 7. Guerrero, 8. Jalisco, 9. México, 10. Michoacán, 11. Morelos, 12. Oaxaca, 13. Nuevo León, 14. Querétaro, 15. San Luis Potosí, 16. Sonora, 17. Tabasco y 18. Yucatán.

Antecedentes

Después de meses de negociaciones en el Congreso de la Unión, la Secretaría de Gobernación [SEGOB] publicó en el Diario Oficial de la Federación [DOF], el 10 de febrero de 2014, el Decreto por el que se reforman, adicionan y derogan diversas disposiciones de la Constitución Política de los Estados Unidos Mexicanos [CPEUM], en materia político-electoral. Por medio de este documento se materializa la reforma a los artículos 26, 28, 29, 35, 41, $54,55,59,65,69,73,74,76,82,83,84,89,93,95,99,102,105$, $107,110,111,115,116,119$ y 122; se adicionaron diversos aspectos a los artículos 26, 41, 69, 73, 74, 76, 89, 90, 99, 105 y 116, además de que se derogó la fracción V del artículo 78, de la Constitución? 7 .

Las principales modificaciones en materia Político Electoral resultantes de esta reforma fueron las siguientes: i. Se crea el Instituto Nacional de Elecciones (INE), que sustituye al IFE en la organización y vigilancia de las elecciones federales. El instituto en su nueva versión designará la integración de los órganos locales para las elecciones estatales y podrá atraer elecciones locales en caso de que lo considere pertinente. El número de consejeros electorales federales pasa de nueve a 11 con una duración de nueve años en el cargo; ii. Los organismos públicos locales electorales estarán integrados por un consejero Presidente y 6 consejeros electorales; todos serán nombrados directamente por el INE para un periodo de

6 Cfr. Capítulo V, Apartado Vigésimo Segundo de los L

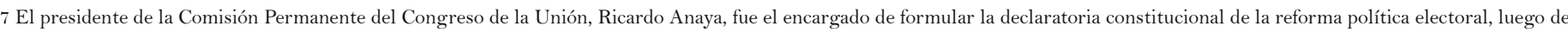
que fue aprobada por la mayoría de los congresos locales del país. Cfr. La Jornada, 22 de enero del 2014.ineamientos 
siete años, sin reelección.

Otros aspectos relevantes, serían que: iii. En un plazo máximo de dos años después de aprobada la reforma en cuestión, la Procuraduría General de la República se convertirá en Fiscalía General de la República como órgano público autónomo, dotado de personalidad jurídica y de patrimonios propios. Contará con dos fiscalías especializadas: una en delitos electorales y otra en combate a la corrupción. Su titular será nombrado por dos terceras partes del Senado y podrá ser removido por el presidente, con el aval de la mayoría calificada de la Cámara alta; iv. A partir de 2018, se otorga autonomía constitucional al Consejo Nacional de Evaluación de la Política de Desarrollo Social (CONEVAL); v. El Senado tendrá que ratificar la estrategia nacional de seguridad del Presidente y éste tendría que informar anualmente de los resultados.

Respecto de la polémica de la reelección, se dispuso en el nuevo ordenamiento que: vi. Los Senadores pudieran ser electos hasta por dos periodos consecutivos, a partir de 2018 y los Diputados al Congreso de la Unión hasta por cuatro periodos consecutivos, a partir de 2015. En ambos casos hasta un máximo de 12 años de manera consecutiva; vii. Se faculta al Presidente de la República para que, en cualquier momento, pueda optar por un gobierno de coalición con uno o varios de los partidos políticos representados en el Congreso de la Unión; viii. Se aumenta del 2 al 3\% el porcentaje mínimo de votos requerido a los partidos políticos para conservar su registro. Además, todo partido político que alcance el 3\% del total de votos válidos emitidos tendrá derecho a que le sean atribuidos diputados plurinominales.

En el apartado de las candidaturas independientes, un tema rezagado en las reformas políticas, se consideró que: ix. para el registro de este tipo de candidatos que deseen participar por el cargo de Presidente de la República deberán contar con el 1\% de las firmas de la lista nominal de electores y $2 \%$ para otros cargos de elección popular; x. Se establece que una elección podrá anularse cuando rebase el tope de gastos de campaña o compra de propaganda en medios, siempre que se determine que la falta fue "sistemática" y "determinante" para el resultado de la elección; xi. Los partidos políticos deberán garantizar la paridad entre géneros en candidaturas a legisladores federales y locales (la cuota todavía vigente se fijó en 2007 con 60- 40, mientras que entre 1996 y 2007 fue de 70-30); y, xii. Respecto al voto de los mexicanos en el extranjero se precisa que podrán ejercer su derecho para la elección de Presidente, gobernador de las entidades federativas y Jefe de Gobierno del Distrito Federal bajo las modalidades de voto personal en los consulados, embajadas y centros de votación autorizados o por el servicio postal, entre otras modificaciones reglamentarias.

Con base en esta serie de modificaciones constitucionales, fue que el 4 de abril del 2014 sesionó por primera vez el consejo general del INE para realizar la toma de protesta del consejero presidente, de los consejeros electorales y de los representantes de los partidos políticos integrados en ese órgano deliberativo. Con el quorum de 16 asistentes, a las 14:00 horas de ese día, Lorenzo Córdova Vianello procedió a tomar protesta como nuevo presidente de la autoridad electoral. Los consejeros designados por la Cámara de Diputados para un periodo de nueve años fueron: Adriana Margarita Favela Herrera, José Roberto Ruíz Saldaña y Ciro Murayama Rendón. Los que fueron designados por seis años fueron: Marco Antonio Baños Martínez y Benito Nacif Hernández (ambos exconsejeros del extinto IFE), además de Enrique Andrade González y Alejandra Pamela San Martín Ríos y Valles; finalmente, los que se integrarían por tres años serían: Beatriz Eugenia Galindo Centeno, Arturo Sánchez Gutiérrez y Javier Santiago Castillo ${ }^{8}$.

Así, tenemos que la reforma política del 2014 atribuyó al consejo general del INE una serie de facultades sobre la propia reglamentación interna con la que se realizarían las designaciones de los consejeros de los OPLES. Resultó por demás evidente, que el poder de decisión y legitimación del ejercicio del poder de este órgano atiende a la definición weberiana de la racionalidad formal ${ }^{9}$. Como se observará en adelante, la dinámica del procedimiento promueve una relación dialéctica entre la aplicación exhaustiva de una reglamentación interna (propuesta por el consejo general del INE para ordenar el procedimiento de selección) y la legitimidad que de ella obtendrían el consejo y los propios miembros de los OPLES.

Este procedimiento de selección, de minuciosa reglamentación, inicia un mes y veinte días después (23 de mayo de 2014) de que se publica en el DOF el Decreto por el que se expide la Ley General de Instituciones y Procedimientos Electorales [LEGIPE], iniciando su vigencia al día siguiente. Posteriormente, para el 11 de marzo de 2015, el Consejo General del INE emitió el acuerdo por el que se aprobaba el reglamento ${ }^{10}$ para la designación y la remoción de las y los consejeros de los OPLES. En el caso del OPLE de Chihuahua, fue hasta el 25 de marzo de 2015, cuando el consejo general del INE aprobara la convocatoria para la designación del consejero presidente y de los consejeros electorales numerarios de este organismo ${ }^{11}$.

La propia comisión de vinculación con los OPLES propuso al consejo general, el 5 de junio del 2015, que su presidente fuera el Mtro. Arturo Sánchez Gutiérrez y como integrantes numerarios quedarían: la Mtra. Adriana Margarita Favela Herrera, el Mtro.

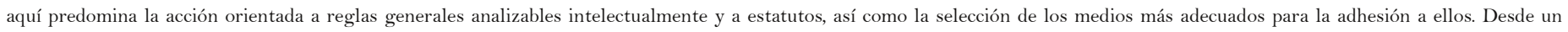

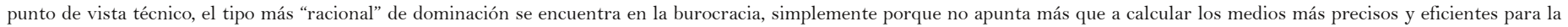


Marco Antonio Baños Martínez y el Dr. Ciro Murayama Rendón ${ }^{12}$. Posteriormente, 17 de junio de 2015, el mismo consejo aprobó el acuerdo por el que se ratificó la rotación de las presidencias de sus comisiones permanentes. Este documento vino a modificar la integración de la comisión temporal de reglamentos y creó la comisión temporal de presupuesto. Sin embargo, la comisión de vinculación con los OPLES quedó integrada en los términos en los que había sido propuesta el 5 de junio anterior ${ }^{13}$.

Un mes y unos días más tarde, para el 13 de julio del mismo año, el consejo aprobó los lineamientos para la aplicación y evaluación del ensayo presencial que presentarían las 25 mujeres aspirantes y los 25 hombres aspirantes de cada entidad federativa que obtuvieron la mejor puntuación en el examen de conocimientos en el proceso de selección y designación a los cargos de consejero presidente y de consejeros electorales numerarios para las 13 entidades siguientes: Aguascalientes, Baja California, Chihuahua, Coahuila, Durango, Hidalgo, Nayarit, Puebla, Quintana Roo, Sinaloa, Tamaulipas, Tlaxcala y Veracruz. En este documento se estableció, para mejorar la legitimidad del proceso, que la institución de educación superior responsable de la aplicación y calificación de los ensayos fuera el Centro de Investigación y Docencia Económicas, A.C. $(\mathrm{CIDE})^{14}$.

Para el 29 de julio se aprobaron los Criterios para realizar la valoración curricular y entrevista los aspirantes que habían accedido a dicha etapa ${ }^{15}$. Luego, para finales de septiembre, se aprobó el Calendario de entrevistas de los aspirantes que accedieron a la etapa de valoración curricular y entrevista en el marco del proceso de selección y designación de los consejeros de los OPLES en los estados de Chihuahua, Coahuila, Nayarit, Puebla y Quintana Roo ${ }^{16}$. Y, finalmente, para el 26 de octubre, la comisión de vinculación con los OPLES, aprobó un proyecto de acuerdo por el que se proponía al consejo general la designación de los consejeros del órgano superior de dirección electoral en el estado de Chihuahua.

\section{Los consejeros electorales del OPLE Chihuahua}

En el caso del estado de Chihuahua, el número de personas que se interesaron en participar en la convocatoria para integrar los OPLES en esta segunda edición ${ }^{17}$ fue de 167 (se registraron 66 mujeres y 101 hombres $)^{18}$. Con un margen de tiempo para el registro muy limitado que proporcionaba la convocatoria ${ }^{19}$, para los dos procesos de selección (2014 y 2015) el consejo general del INE consideró seguir el mismo procedimiento: i. el registro de aspirantes; ii. La aplicación del examen de conocimientos; iii. Aplicación del examen de conocimientos gerenciales; iv. Elaboración de ensayo presencial; y v. las designaciones se propusieron en dos fechas distintas: 8 entidades para el 2 de septiembre y las restantes 5 para el 30 de octubre del 2015.

Los candidatos que aprobaran la tercera etapa del ensayo (evaluado por una institución académica de prestigio), serían los últimos 50 (25 hombres y 25 mujeres) quienes se presentarían a una entrevista cara a cara con los consejeros del propio instituto nacional. Finalmente serían los propios consejeros del INE quienes, a partir de la evidencia recabada decidieran quiénes se integrarían como consejeros presidentes y consejeros electorales a los órganos deliberativos de los OPLES $^{20}$. Un detalle relevante que no debe escapar al análisis de este tipo de procesos, es la dimensión del ejercicio del poder que escapa a las reglas formales. Es decir, que una cosa será el proceso formal de selección en el que participan todos, con una postura (Giddens, 1984) asignada por la reglamentación y, la otra, la cadena de mando de ejercicio del poder real. Aquí habría que agregar que se trata del ejercicio del poder estratégico; los agentes no ejercen el poder ciegamente: el poder por el poder.

Lo que los actores estratégicos de la política buscan es incluir al mayor número posible de miembros de su partido en los órganos deliberativos y de toma de decisiones de los procesos electorales. Un ejemplo de este proceso, por demás evidente, fue la selección previa del consejero presidente y de los consejeros electorales para el OPLE del estado de Chihuahua; no se trataba de integrar a los ciudadanos con los mejores perfiles para desempeñarse en el cargo: se trataba de seleccionar a los miembros del partido que decide sobre el proceso (PRI) con el perfil y la experiencia para integrarse en ese órgano.

Tabla 1

Integración final del órgano superior

de dirección del Organismo Público Local Electoral del estado de Chihuahua

\begin{tabular}{lcc}
\hline \multicolumn{1}{c}{ NOMBRE } & CARG0 & PERÍ0D0 \\
\hline ARTURO MERAZ GONZALEZ & Consejero Presidente & 7años \\
SAÚl EDUARDO RODRIGUEZ & Consejero Electoral & 6años \\
CAMACH0 & & \\
GILBERTO SÁNCHEZ ESPARZA & Consejero Electoral & 6años \\
CLAUDIA ARLET XXESPINO & Consejero Electoral & 6años \\
ALONSO BASSANETTI VILLALOBOS & Consejero Electoral & 3años \\
MAŔ́A ELENA CÁRDENAS MÉNDEZ & Consejero Electoral & 3años \\
JULIETA FUENTES CHÁVEZ & Consejero Electoral & 3años \\
\hline
\end{tabular}

Fuente: Acuerdo del Consejo General del Instituto Nacional Electoral por el que se aprueba la designación del consejero presidente y las consejeras y los consejeros electorales del órgano superior de dirección del Organismo Público Local Electoral del estado de Chihuahua' del 30 de octubre del 2015.

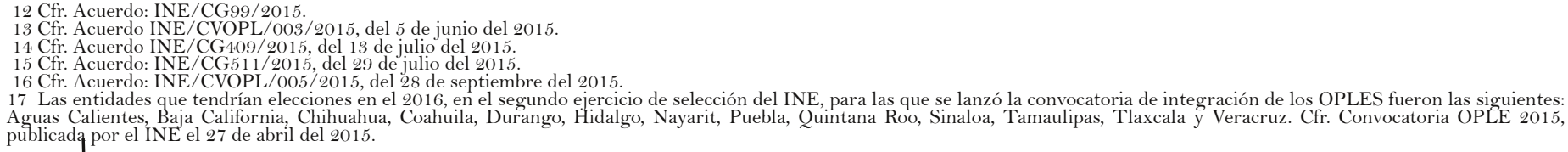

18 Vol. 9 Núm. 16 Enero-junio 2019 
Elementos que se deben integrar a la explicación del proceso: la centralización (se eligió como consejero presidente a un funcionario del IFE-INE-RFE con 23 años de experiencia en el manejo de procesos electorales); la 'renovación' (fue eliminado de la contienda, en la etapa de las entrevistas, el consejero presidente anterior quien deseaba mantenerse en el mismo cargo de consejero presente ahora del OPLE); la legitimación (se realiza un proceso de selección por medio de una convocatoria, con tiempos y etapas prescritos, que atienden a la racionalidad de los procesos burocráticos, pero que el fondo atienden al ejercicio del poder); y, el ejercicio del poder; para la integración del OPLE fueron seleccionados políticos profesionales pertenecientes al partido que decide sobre los agentes que se deben integrar al órgano deliberativo [Ver la tabla 2 que sigue].

Tabla 2

Síntesis curricular de la integración final del órgano superior de dirección del Organismo Público Local Electoral del estado de Chihuahua

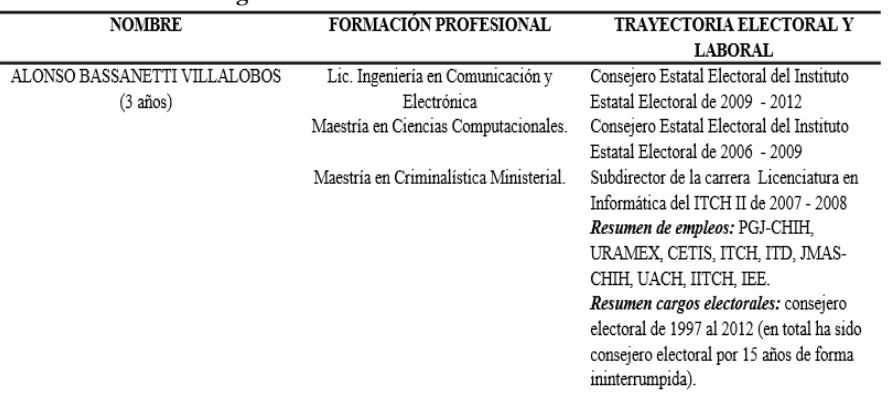

\begin{tabular}{|c|c|c|}
\hline MARÍA ELENA CÁRDENAS MÉNDEZ & Lic. Derecho. & Ha Trabajado en el gobierno del Estado de \\
\hline (3 años) & Maestria en Derecho Constitucional & y Chihuahua en las áreas de desarrollo \\
\hline & Administrativo. & Urbano y administración y en el gobierno \\
\hline & & Federal como funcionaria en las secretarias \\
\hline & & de Desarrollo social, Relaciones Exteriores, \\
\hline & & Gobernación, Educación Pública. \\
\hline & & Resumen de empleos: Desarrollo Urbano \\
\hline & & en el gobierno de Chihuahua, Secretaria de \\
\hline & & Desarrollo Social, Secretaria de Relaciones \\
\hline & & Exteriores, Secretaria de Gobernación y \\
\hline & & Secretaria de Educación Pública. \\
\hline & & Resumen cargos electorales: ninguno. \\
\hline JULIETA FUENTES CHÁVEZ (3 años) & Lic. Relaciones Comerciales. & Jefa de Proyecto de Capacitación Colegio \\
\hline & & de Educación Profesional Técnica del \\
\hline & & Estado de Chihuahua, Plantel Chihuahua II, \\
\hline & & 2006 a la fecha. \\
\hline & Maestría en Mercadotécnica. & Consejera Electoral Propietario en el 06 \\
\hline & & Distrito Federal en el Proceso Electoral \\
\hline & & $2002-2003$ \\
\hline & & Consejera Electoral Propietario en la \\
\hline & & Asamblea General del Instituto Estatal \\
\hline & & Electoral en el Proceso Electoral \\
\hline & & Extraordinario 2001-2002. \\
\hline & & Resumen de empleos: CONALEP, UTCH, \\
\hline & & SEP, UACH (Directivo), Pensiones Civiles \\
\hline & & del Estado. \\
\hline & & Resumen cargos electorales: consejera \\
\hline & & electoral en el periodo 1999-2003 (en total \\
\hline & & ha sido consejera electoral por 5 años de \\
\hline & & forma ininterrumpida). \\
\hline
\end{tabular}

\begin{tabular}{|c|c|c|}
\hline NOMBRE & FORMACION PROFESIONAL & $\begin{array}{l}\text { TRAYECTORIA ELECTORAL Y } \\
\text { LABORAL }\end{array}$ \\
\hline ARTURO MERAZ GONZALEZ (7 años) & $\begin{array}{c}\text { Maestria en Procesos e Intuiciones } \\
\text { Electorales. }\end{array}$ & $\begin{array}{l}\text { Vocal del Registro Federal de Electores de } \\
\text { Junta Local Ejecutiva en Chihuahua. INE } \\
\text { Abril } 2014 \text { a la fecha. } \\
\text { Vocal del Registro Federal de Electores de } \\
\text { Junta Local Ejecutiva en Chihuahua. IFE } \\
1999 \text { a marzo } 2014 \text {. } \\
\text { Director de Centro Regional de Cómputo } \\
\text { Chihuahua - Durango. IFE } 1993 \text { - } 1999 \text {. } \\
\text { Resumen de empleos: IFE, INE (1993- } \\
\text { 2015). } \\
\text { Resumen cargos electorales: funcionario } \\
\text { de la estructura del servicio profesional } \\
\text { electoral en el IFE - INE de } 1993 \text { al } 2015 . \\
\text { (En total ha sido funcionario electoral por } \\
22 \text { años de forma ininterrumpida). }\end{array}$ \\
\hline \multirow[t]{3}{*}{$\begin{array}{l}\text { SAÚl EDUARDO RODRIGUEZ } \\
\text { CAMACHO ( } 6 \text { años) }\end{array}$} & Lic. Derecho. & $\begin{array}{l}\text { Director General Juridico del Supremo } \\
\text { Tribunal de Justicia, adscrito a Presidencia, } \\
\text { Poder Judicial del Estado de Chihuahua, } \\
2014 \text { a la fecha. }\end{array}$ \\
\hline & Esp. Derecho Constitucional. & $\begin{array}{l}\text { Secretario proyectista con funciones de } \\
\text { acuerdos de la Sala de Control } \\
\text { Constitucional del Supremo Tribunal de } \\
\text { Justicia, Poder Judicial del Estado de } \\
\text { Chihuahua, Marzo de } 2014 \text { a agosto } 2014 \text {. }\end{array}$ \\
\hline & Maestria en Derecho. & $\begin{array}{l}\text { Secretario Ejecutivo de Instituto Electoral } \\
\text { de Chihuahua, Octubre de } 2009 \text { a marzo } \\
2014 . \\
\text { Resumen de empleos: Tribunal Estatal } \\
\text { Electoral de Chihuahua (TEE-CHIH); } \\
\text { Instituto Estatal Electoral de Chihuahua } \\
\text { (IEE-CHIH); y, Supremo Tribunal de } \\
\text { Justicia del Poder Judicial del Estado de } \\
\text { Chihuahua (STJ-PJECH). } \\
\text { Resumen cargos electorales: TEE-CHIH; } \\
\text { IEE-CHIH; y, STJ-PJECH. }\end{array}$ \\
\hline \multirow[t]{2}{*}{$\begin{array}{c}\text { GILBERTO SÁNCHEZ ESPARZA (6 } \\
\text { años) }\end{array}$} & Lic. Ingeniería en Electrónica. & $\begin{array}{l}\text { Consejero Propietario del } 06 \text { Distrito } \\
\text { Electoral de Chihuahua por el INE para el } \\
\text { proceso electoral } 2014 \text { - } 2015 .\end{array}$ \\
\hline & Maestria en Administración. & $\begin{array}{l}\text { Consejero Propietario de la Asamblea } \\
\text { Municipal Chihuahua del IFE para el } \\
\text { proceso electoral } 2009 \text { - } 2010 \text {. } \\
\text { Consejero Propietario del } 06 \text { Distrito } \\
\text { Electoral del Estado de Chihuahua por el } \\
\text { IFE para los procesos electorales } 2005- \\
2006,2008-2009 \text { y } 2011-2012 . \\
\text { Resumen de empleos: empresario; USEM; } \\
\text { COPARMEX, Desarrollo Económico del } \\
\text { Gobierno de Chihuahua. } \\
\text { Resumen cargos electorales: consejero } \\
\text { electoral de } 2005 \text { al } 2015 \text { (en total ha sido } \\
\text { consejero electoral por } 10 \text { años de forma } \\
\text { ininterrumpida). }\end{array}$ \\
\hline \multirow[t]{3}{*}{ CLAUDIA ARLET XX ESPINO (6 años) } & Lic. Derecho. & $\begin{array}{l}\text { Profesora de Tiempo Completo como } \\
\text { Docente e Investigadora, de la Universidad } \\
\text { Autónoma de Chihuahua (UACH), } 2003 \text { a } \\
\text { la fecha. }\end{array}$ \\
\hline & Maestria en Derecho Financiero. & $\begin{array}{l}\text { Evaluadora de los comités } \\
\text { Interinstitucionales de la Evaluación de la } \\
\text { Educación Superior (CIEEES) } 2010 \text { a la } \\
\text { fecha. }\end{array}$ \\
\hline & Candidata a Doctora en Derecho. & $\begin{array}{l}\text { Asesora Juridica y Enlace de Genero de la } \\
\text { Coordinación de Comunicación Social del } \\
\text { Gobierno del Estado de Chihuahua } 2011 \text { - } \\
2013 \\
\text { Resumen de empleos: Senado de la } \\
\text { República, Gobierno de Chihuahua, UACH- } \\
\text { Docente, UACH-funcionaria. } \\
\text { Resumen cargos electorales: ninguno. }\end{array}$ \\
\hline
\end{tabular}

Fuente: Acuerdo del Consejo General del Instituto Nacional Electoral por el que se aprueba la designación del consejero presidente y las consejeras y los consejeros electorales del órgano superior de dirección del Organismo Público Local Electoral del estado de Chihuahua y las síntesis curriculares de cada uno de los candidatos. Cfr. $\quad$ www.ine.mx/; http://www.ieechihuahua.org.mx/estructura_2.

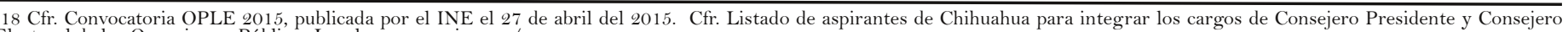
Electoral de los Organismos Públicos Locales en www.ine.mx/.

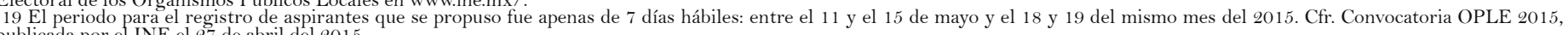

20 Cfr. Acuerdo: INE/CG392/2015, del 17 de junio del 2015. 
Dos preguntas pertinentes debemos hacernos en este momento: De haberse realizado una selección de consejeros electorales como la anterior en todas las entidades, ¿qué se espera que ocurra con la credibilidad y legitimidad de los órganos deliberativos electorales responsables de organizar las elecciones locales? ¿En qué sentido incidirán, los OPLES de integración semejante en los procesos electorales locales, en el proceso de la transición democrática mexicana? Un buen ejemplo de lo que podría ocurrir, además de los reclamos de los propios partidos previos a la consagración de esta figura, fue la anulación de elección local del 6 de junio en el estado de Colima. El litigio que emprendió el PAN en contra del gobernador priísta, por favorecer a su candidato en el proceso electoral, debió ser dirimido en el Tribunal Electoral del Poder Judicial de la Federación [TRIFE]; no hubo nada que el Organismo Público Local Electoral del estado [OPLE] responsable pudiera hacer para controlar el proceso.

Al respecto el magistrado ponente Manuel González Oropeza del TRIFE consideró en su dictamen que: 'La nulidad se da en apego al artículo 59 de la Constitución local y 134 de la Constitución Federal. El solo hecho de haber intervenido los servidores públicos genera motivo de nulidad, esto es una consecuencia y la consecuencia no se puede evitar". Por su parte, la magistrada María del Carmen Alanís dijo que: "quedó demostrada la injerencia del gobernador al implementar un operativo a favor de un partido político en plena campaña electoral”. De igual forma, señaló que se demostraron las declaraciones del procurador que buscan intimidar al electorado y que "tenemos la convicción de que la actuación del procurador incidió en el proceso electoral" 21 .

De acuerdo con lo que se pude observar en la tabla anterior, respecto de los perfiles de las personas que fueron seleccionadas para ocupar los cargos de consejero presidente y consejeros numerarios, todos ellos: i. Poseen un nivel educativo medio (han alcanzado el grado de maestría); ii. Desconocen el ámbito científico y/o académico; y, iii. Pertenecen a la clase política de la entidad (según se desprende de los antecedentes laborales, todos ellos pertenecen a la clase política hegemónica local). Así, tenemos que en el grupo de personas seleccionadas no se observa algún ciudadano sin adscripción político-partidista; todos ellos cuentan con una probada incondicionalidad institucional y una larga trayectoria en el gobierno y en la gestión de los procesos electorales locales.

De los datos que se presentan se puede inferir que los OPLES, no obstante que la nueva reglamentación buscaba eliminar la injerencia de los gobernadores en el proceso de selección, siguen en poder de la clase política de la localidad; se mantiene el control del proceso mediante la influencia directa del partido en el gobierno (PRI) sobre los consejeros. Esto debido a que ellos, los propios 'consejeros electorales', pertenecen a ese grupo político; han sido funcionarios electorales (en los proceso previos) y funcionarios del gobierno.

Sobre los actores que intervienen en el debate: Lorenzo Córdova Vianello [Consejero Presidente]; Enrique Andrade González, Marco Antonio Baños Martínez, Adriana Margarita Favela Herrera, Beatriz Eugenia Galindo Centeno, Ciro Murayama Rendón, Benito Nacif Hernández, José Roberto Ruiz Saldaña, Alejandra Pamela San Martín Ríos y Valles, Arturo Sánchez Gutiérrez y Javier Santiago Castillo [Consejeros Electorales]; Diputado Arturo Álvarez Angli, Diputado Luis Alfredo Valles Mendoza, Diputado Rodrigo Abdala Dartigues y Diputado Gonzalo Guízar Valladares [Consejeros del Poder Legislativo]; Francisco Gárate Chapa, representante propietario del Partido Acción Nacional; Jorge Carlos Ramírez Marín, representante propietario del Partido Revolucionario Institucional (así como el representante suplente, Alejandro Muñoz García); Pablo Gómez Álvarez, representante propietario del Partido de la Revolución Democrática; Pedro Vázquez González, representante propietario del Partido del Trabajo; Jorge Herrera Martínez, representante propietario del Partido Verde Ecologista de México; Juan Miguel Castro Rendón, representante propietario de Movimiento Ciudadano; Marco Alberto Macías Iglesias, representante suplente de Nueva Alianza; Horacio Duarte Olivares, representante propietario de MORENA; Berlín Rodríguez Soria, representante propietario de Encuentro Social y Ricardo Espinoza López, representante propietario del Partido Humanista (así como el representante suplente C. Alberto Marcos Carrillo Armenta); y, Edmundo Jacobo Molina, Secretario del Consejo del Instituto Nacional Electoral ${ }^{22}$.

Sobre los actores que fueron objeto del debate analizado: los consejeros electorales para el OPLE de Chihuahua: Arturo Meraz González, Saúl Eduardo Rodríguez Camacho, Gilberto Sánchez Esparza, Claudia Arlett XX Espino, Alonso Bassanetti Villalobos, María Elena Cárdenas Méndez y Julieta Fuentes Chávez; el primero será presidente por 7 años, los siguientes tres serán consejeros numerarios y permanecerían en el cargo por 6 años y, los tres consejeros restantes lo harían por tres ${ }^{23}$.

\section{La 'defensa discursiva' en órganos deliberativos}

En el análisis que sigue se propone una aproximación al concepto de 'la defensa discursiva' para órganos deliberativos electorales en México. Para tal efecto se presentan las categorías emergentes

21 Cfr. Convocatoria OPLE 2015, publicada por el INE el 27 de abril del 2015.

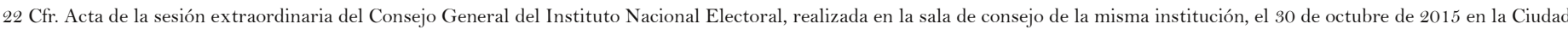
de México, Distrito Federal.

23 Ídem, p. 785

20 Vol. 9 Núm. 16 Enero-junio 2019 
denominadas: 'elementos legitimadores' [de autoridad y cualidad] y 'estrategias discursivas' [descentramiento y repetición]. Para efectos del análisis, en adelante se exponen las categorías codificadas siguientes: i. EL/de autoridad; ii. EL/de cualidad; iii. ED/descentrar; $\mathrm{y}$, iv. ED/repetición. La primera de ellas identifica el fenómeno discursivo que busca legitimar el acto de decidir en favor de $\mathrm{X}$ [de los proponentes] a partir del elemento de autoridad; en la segunda de ellas el fenómeno alude a las cualidades del agente [fenómeno o proceso] que se defiende; la tercer de ellas, será el proceso mediante el cual se elimina el objeto de polémica y se le sustituye por otro que debería ser irrelevante para la disputa verbal; y, la última, como su nombre lo indica, será la estrategia de repetir, en un periodo contextual breve, el fenómeno o el sentido en el que se desea.

La construcción de las categorías que se presentan en este apartado tiene como base las 'razones' que los agentes esgrimieron, en el momento de la exposición de motivos, para actuar en el sentido en el que lo hicieron ['a favor' o 'en contra' de las designaciones de los consejeros integrantes de los OPLES]. Así, a cualquier fenómeno que se pudiera identificar en el corpus discursivo como la 'razón' de un acto propio anterior, en adelante le denominaremos 'elemento legitimador' o 'estrategia discursiva'; se trataría, de fenómenos o elementos legitimadores de un acto individual previo, el 'de aceptar' o ‘de rechazar' la nominación y/o designación de un consejero.

\section{La contradicción entre 'principios' y 'requisitos'}

Lo que se puede observar en la propia reglamentación interna del INE-OPLE, es que presenta una contradicción entre los 'principios' del Instituto y los requisitos de elegibilidad de los consejeros presidentes y de los consejeros electorales de los OPLES. Así, se tiene por una parte que, de acuerdo con lo que se señala en el párrafo 2 del artículo 30 de la LEGIPE, 'todas las actividades del Instituto se regirán por los principios de certeza, legalidad, independencia, imparcialidad, máxima publicidad y objetividad'. Y, por la otra, se dispone en el artículo 100.2 que:

'los requisitos para ser consejero electoral local son los siguientes: a) Ser ciudadano mexicano por nacimiento, que no adquiera otra nacionalidad, además de estar en pleno goce de sus derechos civiles y políticos; b) Estar inscrito en el Registro Federal de Electores y contar con credencial para votar vigente; c) Tener más de 30 años de edad al día de la designación; d) Poseer al día de la designación, con antigüedad mínima de cinco años, título profesional de nivel licenciatura; e) Gozar de buena reputación y no haber sido condenado por delito alguno, salvo que hubiese sido de carácter no intencional o imprudencial; f)
Ser originario de la entidad federativa correspondiente o contar con una residencia efectiva de por lo menos cinco años anteriores a su designación, salvo el caso de ausencia por servicio público, educativo o de investigación por un tiempo menor de seis meses; g) No haber sido registrado como candidato ni haber desempeñado cargo alguno de elección popular en los cuatro años anteriores a la designación; h) No desempeñar ni haber desempeñado cargo de dirección nacional, estatal o municipal en algún partido político en los cuatro años anteriores a la designación; i) No estar inhabilitado para ejercer cargos públicos en cualquier institución pública federal o local; j) No haberse desempeñado durante los cuatro años previos a la designación como titular de secretaría o dependencia del gabinete legal o ampliado tanto del gobierno de la Federación o como de las entidades federativas, ni subsecretario u oficial mayor en la administración pública de cualquier nivel de gobierno. No ser Jefe de Gobierno del Distrito Federal, ni Gobernador, ni Secretario de Gobierno o su equivalente a nivel local. No ser Presidente Municipal, Síndico o Regidor o titular de dependencia de los ayuntamientos, y k) No ser ni haber sido miembro del Servicio Profesional Electoral Nacional durante el último proceso electoral en la entidad'.

Luego entonces, la contradicción se deduce del hecho de que no será posible el cumplimiento de los principios superiores que guían al Instituto [certeza, legalidad, independencia, imparcialidad, máxima publicidad y objetividad], cuando se permite que los miembros [o simpatizantes] de algún partido se integren como consejeros al consejo general de las OPLES. En el caso que nos ocupa, todos los cargos del consejo general del OPLE Chihuahua fueron ocupados por prístas (Ver tabla 1 y 2); algunos de ellos inscritos en el padrón de miembros de ese partido (aunque después lo negaran y el argumento se les aceptara) y otros, aunque no contaran con ese registro, ocupaban o habían ocupado cargos en los gobiernos estatal y/o municipales del PRI.

Pero ¿cómo se explican las implicaciones que este fenómeno para la credibilidad y legitimidad del INE-OPLES (y de la democracia electoral en general) la designación de agentes con este perfil? 1. Que los consejos generales de los OPLES son órganos deliberativos; 2. Que en tales órganos se toman las decisiones que atañen al correcto desarrollo de los procesos electorales locales; 3. Que los actos de los consejeros electorales de los OPLES deberían de procurar los principios del Instituto antes señalados; 4. Que los consejeros electorales que pertenecen a un partido político en el consejo general de la OPLE serán juez y parte de los procesos de manera simultánea; 5 . En tanto que pertenecen a una estructura 
partidista, son actores de la política con experiencia y han venido forjando una carrera política bajo la tutela de su partido, no podrán tomar las decisiones que atañen a la sociedad de forma independiente, imparcial y objetiva; y, 6. Se observa la colonización, cuando menos del OPLE analizado, por parte de los miembros del PRI; el reclutamiento de los consejeros del OPLE en mención se ha realizado de entre la membrecía de este partido (con o sin registro en el padrón).

[Todos estos consejeros son miembros del PRI, estén o no registrados en el padrón del partido son miembros del PRI, la evidencia de que pertenecen a ese partido (aunque no estén registrados) es que todos ellos tienen o han tenido empleos en las administraciones priístas. Y podríamos ir más lejos, podríamos suponer que muchos de ellos no cuentan con registro en el padrón del PRI porque se han ido especializado en la administración o la justicia electoral que no ve con buenos ojos que los miembros de los partidos políticos ocupen cargos en los que se requiere de independencia e imparcialidad en la toma de decisiones].

El fenómeno de la 'colonización' de los órganos deliberativos electorales de las OPLES no ha pasado desapercibido para los miembros de la oposición. Cuando menos en el consejo general del INE, y en algunos medios masivos de comunicación, los representantes de los partidos que no participaron de esta distribución de cargos de consejeros, consideraron perjudicial [pernicioso] para los propios procesos electorales este arreglo extralegal de las designaciones en las que participaron como meros observadores. Enseguida presentamos los resultados del análisis de este debate.

\section{Los elementos legitimadores y las estrategias discursivas de los consejeros del CG-INE}

Los elementos legitimadores de una decisión serán las razones que cada uno de los agentes esgrime ante el pleno del CGINE a título personal y tienen el propósito de integrarse, a su vez, como elementos legitimadores de una decisión colectiva de ese órgano colegiado ${ }^{24}$. De acuerdo con los resultados del análisis que se presentan más abajo, los elementos legitimadores se pueden clasificar en tres tipos: i. de autoridad, porque su referente será el del ejercicio de la autoridad y/o de sus propiedades; ii. de cualidad, porque versan sobre los atributos que posee un candidato o prospecto para el OPELE y que se exponen como los 'ideales'; y, iii. de precedentes, porque aluden a los casos anteriores en los que el CG-INE o CG-IFE, al rechazar a ciertos personajes que se desempeñaban como empleados de funcionarios o representantes de los partidos, el TEPJF se vio en la necesidad de revertir una decisión que los marginaba de una actividad o empleo en el ámbito electoral.

Tabla 3

Un ejemplo del procedimiento de categorización

\begin{tabular}{ll}
\hline Corpus discursivo & Categorías \\
\hline $\begin{array}{l}\text { 654] Nosotros tuvimos a cargo la entrevista de Claudia Arleth Espino, el } \\
\text { Consejero Javier Santiago, la Consejera Adriana Favela, el Consejero }\end{array}$ & EL/de autoridad \\
Benito Nacif y un servidor y lo que advertimos en el perfil es la solidez & EL/de cualidad \\
intelectual que tiene esta persona, una travectoria absolutamente académica. & EL/de cualidad \\
con algunas responsabilidades si en temas vinculados, insisto, al cargo de & ED/descentrar \\
senadora de otra persona que la invitó a trabajar al propio Senado de la \\
República, pero no advertimos que existiera alguna situación por la cual no \\
pudiera ser considera como parte de la propuesta para integrar los Órganos
\end{tabular}

Fuente: análisis propio sobre la versión estenográfica de la $\mathrm{X}$ sesión extraordinaria del CG-INE, de fecha Y.

Respecto del elemento legitimador de autoridad (nosotros y la relevancia), tal y como se puede observar en el fragmento 654 anterior, que se retoma como ejemplo del procedimiento de categorización, el primer elemento legitimador que se puede advertir es de autoridad; un grupo de agentes (consejeros) que realizan su trabajo (entrevistas) y que, a partir de él llegan a una conclusión (Nosotros entrevistamos a CAE; [Nosotros] ABCD advertimos que CAE tiene SI y TAA). Este detalle de relevancia discursiva significa que: Nosotros somos la autoridad, que es legítima, que es preponderante dado que aparece en primer término (de allí su relevancia); primero se muestra un pronombre y luego se exponen los tres nombres y otro pronombre 'Un servidor'. En la primera parte de este fragmento no se mencionan las cualidades de la entrevistada o de la candidata, sino que se enuncia al equipo de consejeros electorales del CG-INE que fueron designados por la propia reglamentación para entrevistar a los candidatos a consejeros de OPLES y, para reforzar este elemento, enseguida se enuncia a los consejeros: 'el Consejero Javier Santiago, la Consejera Adriana Favela, el Consejero Benito Nacif y un servidor'.

\section{La estrategia discursiva del descentramiento}

La estrategia discursiva del descentramiento (EDD), como su nombre lo indica, es el acto por medio del cual un agente o emisor quita del centro del debate el fenómeno (objeto, proceso, fenómeno, etc.) impugnado y lo sustituye por otro que siempre (o casi siempre), tiene la característica de ser inimpugnable o inocuo según el contexto de que se trate. Los oponentes consideran que CAE no debería de

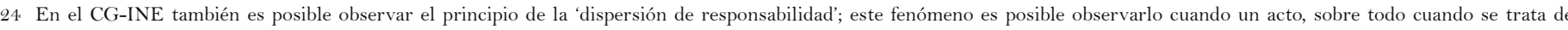

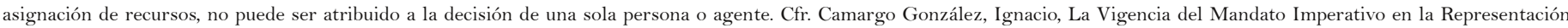
Política Mexicana, México, Instituto de Investigaciones Dr. José María Luis Mora, Tesis de maestría, 2000. 
pertenecer al OPLE de Chihuahua porque es miembro activo del Partido Revolucionario Institucional (PRI) ${ }^{25}$.

[652] Y me parece que es muy importante mencionar/ que en el caso concreto de esta persona, /ciertamente trabajó con la senadora Graciela Ortiz, /pero en eso, /en las actividades del Senado de la República, /como secretaria técnica de una de las comisiones del Senado /donde esta persona fungía.

El proponente MABM implementa la estrategia discursiva del descentramiento cuando en el fragmento anterior [652], señala que CAE 'trabajó con la senadora $\mathrm{GO}$ en las en actividades del Senado de la República como secretaria técnica de una de las comisiones'. Lo que MABM no dice es que la senadora GO pertenece al PRI; que CAE obtuvo el empleo de secretaria técnica de una de las comisiones que presidía la senadora GO del PRI debido a que ella misma (CAE) pertenece al PRI; y, que para todas las plazas, de que pueden disponer los senadores (o diputados), en las comisiones en las que tienen influencia, son seleccionados como empleados los miembros subordinados de su propio partido (PRI).

En el siguiente fragmento utiliza la estrategia del descentramiento para eliminar la evidencia que los oponentes aportaban en contra de CAE: una fotografía en la que aparece con la senadora GO y en la que se les identifica a ambas como miembros del PRI. El mismo proponente MABM, en fragmento que sigue [653] implementa la misma estrategia: 'elementos que fueron circulados para el conocimiento de la Comisión, alguna fotografía que aparece en la página de Facebook de esta aspirante a Consejera Electoral, tiene que ver con una fotografía publicada en el marco de las actividades que ya cumplía dentro del Senado'.

[653] Quiero decir también que si bien hubo algunos, /como dijo la Consejera San Martín, /elementos que fueron circulados para el conocimiento de la Comisión, /alguna fotografía que aparece en la página de Facebook de esta aspirante a Consejera Electoral, tiene que ver con una fotografía publicada en el marco de las actividades que ya cumplía dentro del Senado.

Como se puede observar, se trata de una fotografía que no evidencia la pertenencia de CAE al PRI y que, por el contrario, se trata de una fotografía que ha sido 'descontextualizada' ya que se trata de evidencia publicada en 'el marco de las actividades que ya cumplía dentro del Senado'; es decir, que no existe un vínculo de lealtad entre CAE (que pertenece al PRI) y GO (que es senadora por
PRI), sino entre CAE y el Senado de la República, una institución que evidentemente es distinta del PRI.

\section{Elementos des-legitimadores y legitimadores de cualidad}

Los elementos deslegitimadores, aquellos que los representantes de los partidos esgrimieron en el seno del CG-INE en contra de la designación de CAE, aparecen en la primera parte de la intervención de MABM; enseguida aparecerá el propósito discursivo fundamental que será el de eliminar las objeciones, el de contrarrestar los elementos des-legitimadores de cualidad con el aporte grandilocuente de sus propios elementos legitimadores que se pueden observar en las siguientes categorías: [EL/de autoridad; EL/de cualidad; y, ED/descentrar].

Tabla 4

Las propuestas argumentativas

Irreconciliahles de nrononentes v ononentes

\begin{tabular}{ll}
\hline Proponente & Oponente \\
\hline
\end{tabular}

$\begin{array}{ll}\text { (P1) El PRI es un PP } & \text { (P1*) El PRI es un PP } \\ \text { (P2) CAE es miembro del PRI } & \left(P 2^{*} \text { CAE es miembro del PRI }\right.\end{array}$

(P3) Los miembros de los PP son SI idóneos (P3*) Los miembros de los PP son N0 idóneos para el OPLE para el OPLE

$\therefore(\mathrm{Cl}) \mathrm{CAE}$ es SI idónea para el OPLE $\quad$..(C1*) CAE es NO idónea para el OPLE

Fuente: elaboración propia con base en la categorización de los datos.

En la tabla de arriba se pueden observar, a manera de ejemplo, las propuestas argumentativas de los 'proponentes' y de los 'oponentes'. Tal y como podemos apreciar, las premisas y las conclusiones de ambos tipos de argumentos son válidos; la conclusión se desprende de forma lógica de las premisas en ambos casos. El elemento medular que distingue el formato argumentativo de las 'posiciones irreconciliables' se encuentra en los distintos referentes que los agentes del debate tienen en mente; las reglas formales de la LEGIPE que deben tenerse en cuenta como parte del contexto en el que se emite el discurso. El proponente considera la SI idoneidad de CAE a partir del cumplimiento de ciertos los artículos (A) de la ley (P3); y, los oponentes, por el contrario, consideran la NO idoneidad de CAE a partir del incumplimiento de otros tantos artículos (B) de la misma legislación (P3*).

Un elemento consustancial de este tipo de órganos deliberativos, en los que regularmente se pueden observar tales argumentaciones, es que no existe un árbitro interno y válido que 
señale la veracidad o validez de los argumentos. El debate, los argumentos y los datos que se exponen como evidencia (de la SI o de la NO idoneidad) no tienen más relevancia que la expositiva; el argumento válido, (lógico y/o verdadero) es desplazado por la trampa (en los órganos colegidos democráticos) de la 'regla de la mayoría' que decidirá a fin de cuentas quién o quiénes poseen la razón; si las premisas que se utilizan son adecuadas y/o si las conclusiones a las que llegan los proponentes u oponentes se derivan lógicamente o no, es un asunto que no tiene la mayor relevancia.

Así, todas las personas que fueron seleccionadas por la comisión de vinculación con los OPLES, fueron ratificadas en los cargos para los que fueron apuntados. El debate sobre si las personas propuestas cumplía, o no, con las disposiciones legales de la LEGIPE no tuvo ningún efecto sobre la decisión previa que los consejeros ya tenían; los argumentos de los oponentes no fueron tomados en cuenta por los consejeros del CG-INE para aprobar la integración de los OPLES. Este fenómeno de ejercicio del poder sobre la forma en la que se distribuyen los recursos en juego (de autoridad y de asignación) se deriva del poder de la 'regla de la mayoría' en el diseño institucional de los órganos deliberativos. Por ello es que el debate en el seno del CG-INE tiene más bien una función legitimadora; todas las decisiones que realicen los consejeros del consejo general del INE tendrán el respaldo de 'ser legítimos' debido a que fueron sometidos al 'aparato de la crítica'. En realidad, tal y como hemos señalado más arriba, es irrelevante que una decisión sea o no racional; la conclusión se derive de manera lógica de las premisas; etc. a fin de cuentas los consejeros ya antes han decidido sobre el sentido de su (sus) actos: el diseño les permite sólo a ellos tener voz y voto, al tiempo que la regla de la mayoría sólo se aplica a ellos mismos y no a los representantes de los partidos políticos.

\section{Dos estrategias del consejero MABM: 'la repetición' y 'el temor por los precedentes'}

Dos elementos relevantes debemos agregar a las estrategias discursivas y persuasivas que emergen del corpus discursivo: 'la repetición' y 'el temor a los precedentes'. Con la primera de ellas el emisor pretende convencer a su audiencia, por la multiplicidad de casos en los que los miembros de los PP, según el TEPJF, '...no traiciona, no incumple el principio de imparcialidad...'. En la segunda de ellas es la de 'atemorizar con precedentes' que ha sentado una autoridad. Uno de los consejeros [MABM] defiende la tesis de que los miembros de los partidos políticos no pueden ser imparciales dado que así lo ha dictado una entidad jerárquica superior [TEPJF]: ‘...el más reciente tiene que ver con una persona que fue diputado local suplente y que en la opinión del Tribunal no incumple el requisito de imparcialidad...'. En los párrafos que siguen se muestran ambas estrategias de la defensa de su decisión de aceptar a los miembros del PRI para el OPLE de Chihuahua; se exponen diversos casos en los que el TEPJF ha aceptado a los miembros de partidos políticos para ocupar algún empleo electoral.

[658] Hay diversos casos que ha resuelto el Tribunal en esta materia, desde hace muchos años.

[659] Por ejemplo en alguna ocasión para los cargos del Servicio Civil de Carrera, un joven del estado de Guerrero que en el proceso electoral del 2000 trabajó como asesor de los candidatos a diputados por el principio de representación proporcional del Partido de la Revolución Democrática, así decía su currículum fue excluido de la posibilidad del concurso.

[660] Él fue al Tribunal y el Tribunal dijo que la prestación de servicios profesionales no inhabilita a una persona para ocupar un cargo en el Servicio Civil de Carrera, porque no traiciona, no incumple el principio de imparcialidad al haber colaborado con un partido político. Ese es un caso extremo que me parece que debe ser tomando en cuenta.

[661] Recientemente el Tribunal ha tomado diversos criterios para establecer la manera en que debe ser interpretado el principio de imparcialidad, el más reciente tiene que ver con una persona que fue diputado local suplente y que en la opinión del Tribunal no incumple el requisito de imparcialidad, pese a que fue electo como diputado local suplente. Es un caso de este proceso de selección en el concurso de incorporación.

[662] Hay casos extremos. Tuvimos en el proceso de incorporación anterior, la inscripción de una persona que había trabajo en el Comité Directivo Estatal de un partido político y que había fungido como secretario en la composición de ese Comité Directivo Estatal.

[663] El Tribunal dijo que eso no incumplía tampoco el principio de imparcialidad y ordenó que se hiciera la entrevista respectiva de esa persona.

[664] En el estado de Sonora también hubo casos en los cuales hubo personas que se habían desempeñado como representantes de partido político ante un Consejo Distrital del Instituto Federal Electoral en varias ocasiones y también el Tribunal ha dicho que eso no traiciona el principio de imparcialidad.

[665] En consecuencia, me parece que son elementos que la Comisión de Vinculación toma en consideración para poder hacer el análisis de las propuestas correspondientes y traer a esta mesa las propuestas para la designación de las consejeras y los consejeros electorales.

[666] Coincido respecto del caso del señor Basaneti con los elementos 
que ha presentado el Consejero Murayama.

[667] De mi parte, yo sostendré en el caso concreto de Chihuahua, la propuesta que ha formulado la Comisión de Vinculación y que está siendo revisada en este momento por este Consejo General.
Tal y como se puede observar en los fragmentos arquetipo anteriores, con los que se ejemplifican ambas categorías, el consejero proponente considera como evidencia de imparcialidad los resolutivos del tribunal en favor de los miembros de los partidos. Red 1

Elementos de la persuación: el Consejero General del INE

Las razones (motivos y causas) de los actos, las estrategias discursivas y la conclusión

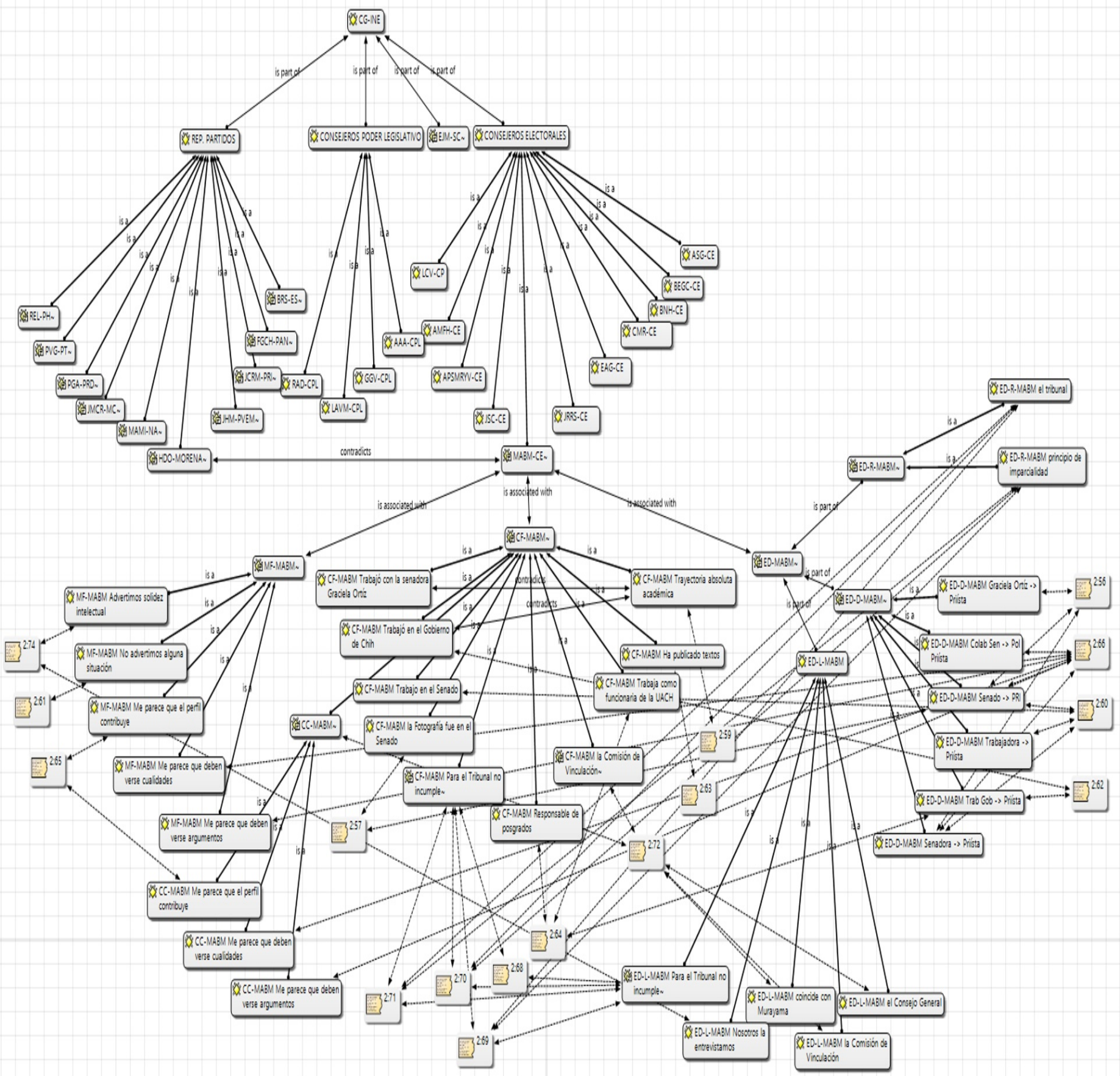

Fuente: elaboración propia a partir de la categorización y el análisis de los datos. 
Luego entonces, serán los resultados favorables de los juicios interpuestos ante el TEPJF por tales agentes, las premisas de una conclusión en la que los miembros del PRI resultan ser agentes imparciales. El emisor del discurso recurre al mecanismo de autoridad [TEPJF] para respaldar una conclusión; si el TEPJF ha afirmado, reiteradamente, que los miembros de los PP son imparciales, luego entonces, los miembros del PRI, que integran el OPLE de Chihuahua, también lo serán. Una serie de argumentos descentrados como los que se presentan en los párrafos anteriores nos indican que, no obstante que el consejero MABM nunca acepta explícitamente que CAE es miembro del PRI, implícitamente sí lo hace al defender la imparcialidad [como principio básico del IFEINE] de los miembros de los PP cuando se desempeñan en empleos electorales.

\section{Consideraciones finales}

El consejo general del INE por sí mismo, como órgano deliberativo sui generis, tiene la función de constituirse como un elemento más del engranaje sistémico de legitimación para la designación de los consejeros electorales de las OPLES. La diversidad de estrategias legitimadores que se implementaron fueron las siguientes: acatar la normatividad, prescribir las reglas que hicieron falta, atender a la máxima transparencia del proceso de selección, exponer las razones en favor de sus decisiones ante el pleno del consejo, etc. Sin embargo, las razones (y los argumentos) que fueron expuestas por algunos de los presentantes de partidos, en contra de las designaciones de consejeros, sobre todo aquellos que proceden del PRI, no tuvieron ningún efecto sobre la decisión que previamente habían tomado los propios consejeros del consejo general

En la estructura discursiva de los consejeros, sobre todo los que fueron identificados como 'proponentes', resulta evidente que los 'principios' básicos con los que debe funcionar el instituto fueron eliminados con los argumentos y las estrategias discursivas que hemos identificado; tan sólo se mencionaron las reglas que contenían los requisitos de elegibilidad (idoneidad). Resulta por demás evidente que si no se atiende a tales principios (imparcialidad, objetividad, etc.), cualquier miembro de partido puede convertirse en juez de los procesos electorales locales. Y, a la inversa, si tales principios hubiesen sido observados por los consejeros del consejo general, ningún miembro del PRI debió haber sido seleccionado para administrar y conocer de los procesos electorales locales.

Es verdad que el poder de decisión sobre quién o quiénes serían los consejeros de los OPLES ya no lo tiene formalmente el gobernador de la entidad (a través de su incidencia en el congreso local); en teoría el poder de decisión ahora lo tiene el consejo general del INE quien, como se ha mostrado más arriba, se propuso legitimar el proceso de selección mediante la racionalidad formal y burocrática. No obstante, según la evidencia que hemos aportado hasta aquí, la decisión sobre quiénes deberán ser los consejeros de estos organismos, sigue en manos de quienes ostentan el poder políticoeconómico en la entidad de origen. Resultaría ilógico pensar que la selección de siete políticos del PRI, como titulares del consejo local electoral, pudo deberse al azar, a una mera coincidencia; sabemos que los consejeros del CG que decidirían tuvieron en sus manos un listado con 29 aspirantes con resultado idóneo [13 mujeres y 16 hombres] que cumplían con los requisitos previstos por la legislación.

Luego entonces ¿Qué implicaciones tendría este defecto (del órgano deliberativo en el consejo general) para la democracia electoral en su conjunto? ¿Qué implicaciones tendría la designación misma como parte de las bases legitimadoras de un proceso electoral local? Lo que se observa es el fortalecimiento e institucionalización de un régimen en el que es preponderante el poder político en la designación de la integración de los órganos decisorios de los procesos electorales locales. El locus del poder de decisión sigue en el mismo lugar; ahora tiene un ropaje distinto que lo legitima (legalidad, máxima transparencia, defensa de los consejeros, etc.), pero sigue donde mismo. Se llegó a considerar que el número de consejeros que podría designar cada partido estaría en función de su peso en la cámara de diputados local (tal y como ocurrió con el consejo general del INE); sin embargo, según lo que se observa, fue el PRI quien pudo decidir y proponer a todos los integrantes de ese consejo de entre sus militantes ${ }^{26}$.

Será pertinente considera que en la configuración de este tipo de régimen electoral, que ha sido colonización por un partido [el derechista PRI], contribuye principalmente un cierto diseño institucional de los órganos deliberativos y la regla de la mayoría que legitima los procesos internos como el que se ha analizado. Uno de los argumentos centrales que se esgrimieron en contra de la designación de CAT, como consejera del OPLE Chihuahua, era que su pertenencia al PRI la imposibilitaba para poder cumplir con el principio rector de la imparcialidad; no obstante el consejo general del INE desechó su pertenencia al PRI; para tal efecto, el dictamen del CG-INE señalaba [y esto coincide con los resultados de nuestro propio análisis] que tal decisión se debía a que armonizaban con la tesis de jurisprudencia $1 / 2015$, emitida por la Sala Superior del Tribunal Electoral del Poder Judicial de la Federación, cuyo rubro es supervisor electoral o capacitador-asistente. La sola verificación del

Cfr. El currículo de cada uno de los aspirantes en el Acta de la sesión extraordinaria del Consejo General del Instituto Nacional Electoral, op. cit., 2015 , pp. 840-857. 
padrón de militantes de los partidos políticos no es suficientes para comprobar su afiliación.

El caso que se toma como ejemplo para el análisis [el de la consejera $\mathrm{CAT}]$, resulta ser una réplica del procedimiento autorreferencial del propio régimen y que ocurrió con los otros 6 consejeros; ninguno de ellos, dada su pertenencia al PRI, podría cumplir con el principio rector de independencia ${ }^{27}$ que tiene como fundamento el funcionamiento del INE. Además de que, en el caso particular de CAT, se podrá configurar también un conflicto de intereses dado que su promotora, la senadora prísta Graciela Ortiz, decidió contender por la candidatura del PRI a la gubernatura del estado de Chihuahua.

\section{Bibliografía}

Acta de la sesión extraordinaria del Consejo General del Instituto Nacional Electoral, realizada en la sala de consejo de la misma institución, el 30 de octubre de 2015 en la Ciudad de México, Distrito Federal.

Acuerdo del Consejo General del Instituto Nacional Electoral por el que se aprueba la designación del consejero presidente y las consejeras y los consejeros electorales del órgano superior de dirección del Organismo Público Local Electoral del estado de Chihuahua, del 30 de octubre del 2015.

Acuerdo INE/CG46/2014.

Acuerdo INE/CG409/2015, del 13 de julio del 2015.

Acuerdo INE/CVOPL/003/2015, del 5 de junio del 2015.

Acuerdo: INE/CG392/2015, del 17 de junio del 2015.

Acuerdo: INE/CG511/2015, del 29 de julio del 2015.

Acuerdo: INE/CG86/2015

Acuerdo: INE/CG99/2015.

Acuerdo: INE/CVOPL/005/2015, del 28 de septiembre del 2015.

Biografía de los consejeros electorales del OPLE Chihuahua.

Consultado el 28 de noviembre del 2015 en: http://www.ieechihuahua.org.mx/estructura_2.

Bolivar Meza, Rosendo, La teoría de las élites en Pareto, Mosca y Michels, en Iztapalapa, No. 52, año 23, enero-junio del 2002, pp. 286-407.

Camargo González, Ignacio, La Vigencia del Mandato Imperativo en la Representación Política Mexicana, México, Instituto de Investigaciones Dr. José María Luis Mora, Tesis de maestría, 2000.

Convocatoria OPLE 2015, publicada por el INE el 27 de abril del 2015.

Decreto por el que se reforman, adicionan y derogan diversas disposiciones de la Constitución Política de los Estados Unidos Mexicanos, en materia política-electoral, en Diario Oficial de la Federación, del 10 de febrero del 2014.

Decreto publicado en el Diario Oficial de la Federación, del 4 de abril del 2014.

http://pri.org.mx/JuntosHacemosMas/NuestroPartido/Miembrosa filiados.aspx, consultado el 07 de enero del 2016.

http://www.ine.mx/archivos3/portal/historico/ contenido/Que_es/\#Principios, consultado el 13 de enero del 2016.

Kalbert, Stephen, La influencia pasada y presente de las visiones del mundo: Max Weber y el descuido de un concepto sociológico, en Sociológica, año 26, número 74, septiembrediciembre del 2011 , pp. 207-246.

La Jornada, 22 de enero del 2014.

Listado de aspirantes de Chihuahua para integrar los cargos de Consejero Presidente y Consejero Electoral de los Organismos Públicos Locales en www.ine.mx/.

Pareto, Vilfredo, Tratado de sociología general (1917-1919), Ginebra, Droz, 1968.

Programa de trabajo de la comisión de vinculación con los 


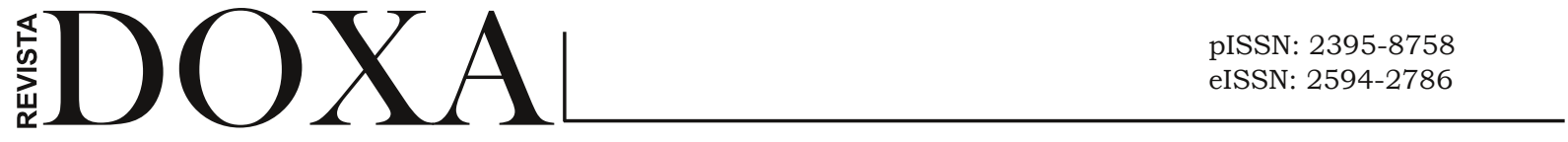

organismos públicos locales. Consultado el 24 de noviembre del 2015 en: http://www.ine.mx/docs/IFEv2/DS/DS-CG/DS-SesionesCG/CG-

acuerdos/2014/Julio/CGex201407-09/CGex201407-

9_ap_2.pdf.

Versión estenográfica de la sesión de instalación del Consejo
General del INE, México, INE, 4 de abril del 2014

Zepeda, Aurora, "Y se cayó la elección en Colima, INE organizará nuevo proceso"; periódico Excélsior del 23 de octubre del 2015 ,

en:

http://www.excelsior.com.mx/nacional/2015/10/23/1052 806. 
Anexo 1

Identificación como miembros del Partido Revolucionario Institucional de uno de los consejeros propuestos para el OPLE Chihuahua

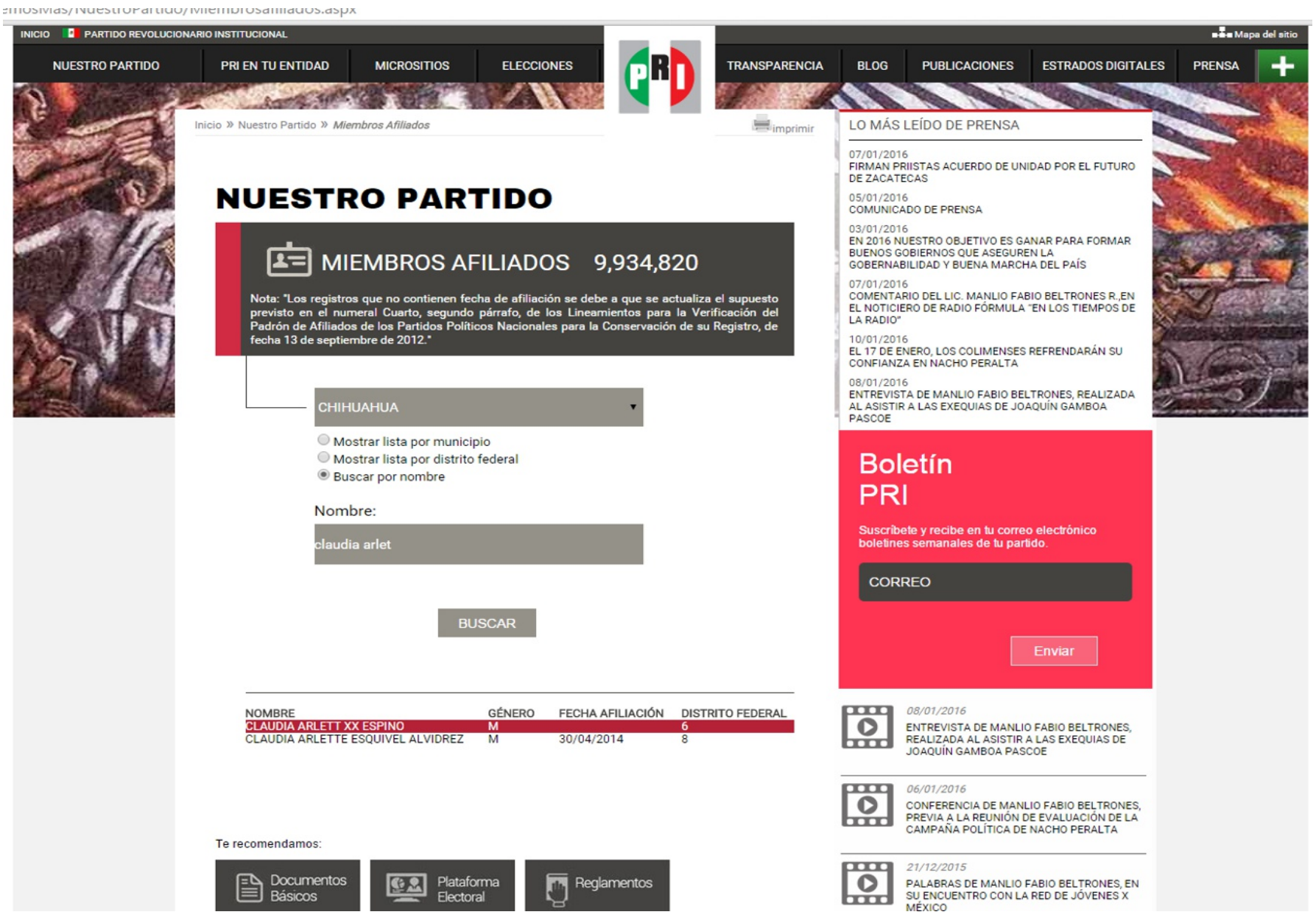

Registro de Claudia Arlet Espino, como miembro del PRI en el distrito VI.

Fuente: http://pri.org.mx/JuntosHacemosMas/NuestroPartido/Miembrosafiliados.aspx. 
Anexo 2

Identificación como miembros del Partido Revolucionario Institucional de uno de los consejeros propuestos para el OPLE Chihuahua

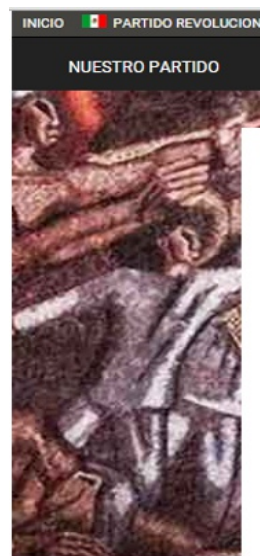

\section{NUESTRO PARTIDO}

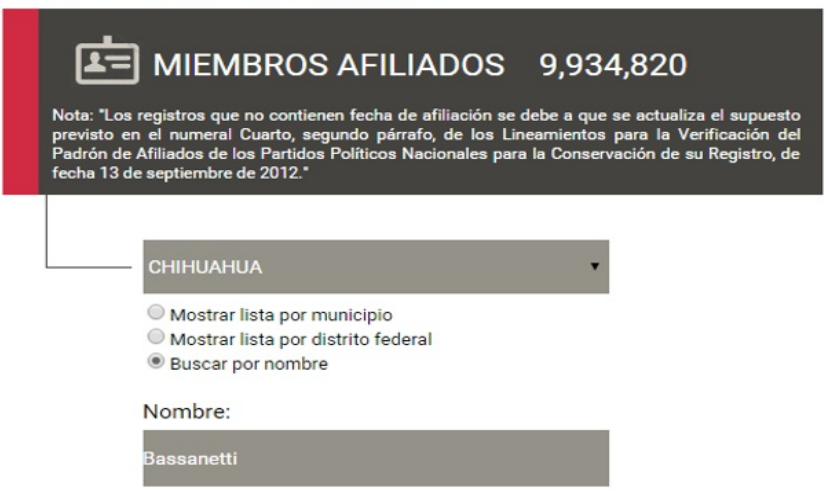

\section{BUSCAR}

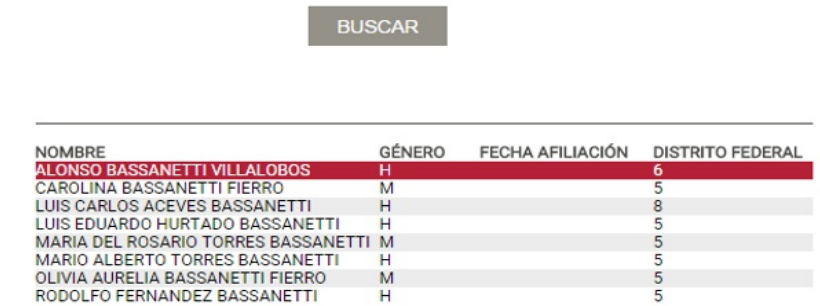

Enviar

\section{Boletín}

PRI

Suscribete y recibe en tu correo electrónico
boletines semanales de tu partido.

CORREO

Th A NZA EN NACHO PERALTA

O8/01/2016 AL ASISTR A LAS EXEQUIAS DE JOAQUIN GAMBOA O8/01/2016
ENTREVISTA DE MANLIO FABIO BELTRONES,
REALIZADA AL ASISTIR A LAS EXEQUIAS DE
JOAQUIN GAMBOA PASCOE

CONFERENCIA DE MANLIO FABIO BELTRONES, CAMPAÑA POLITICA DE NACHO PERALTA-

Tarommondamno

PALABRAS DE MANLIO FABIO BELTRONES, EN MÉXICO

Registro de Alonso Bassanetti Villalobos, como miembro del PRI en el distrito VI.

Fuente: http://pri.org.mx/JuntosHacemosMas/NuestroPartido/Miembrosafiliados.aspx. 